\title{
Pembuatan Biodiesel dengan Proses Ekstraksi Reaktif dari Ampas Perasan Kelapa
}

\author{
Iwan Ridwan*, Meylin, Rima Puspitasari, Dianty Rosirda Dewi, Mukhtar Ghozali \\ *Jurusan Teknik Kimia, Politeknik Negeri Bandung 40559 \\ Jl. Gegerkalong, Ciwaruga, Bandung. Telp/Fax. 0222016403 \\ E-mail : ridwantk@gmail.com
}

\begin{abstract}
ABSTRAK
Biodiesel merupakan energi terbarukan yang berasal dari minyak nabati atau minyak hewani. Pada penelitian ini pembuatan biodiesel dilakukan dengan metode ekstaksi reaktif (transesterifikasi in situ). Bahan baku yang digunakan yaitu ampas perasan kelapa dengan bilangan asam $0,5426 \mathrm{mg}$ $\mathrm{KOH} / \mathrm{g}$, diameter partikel sebesar $1,12 \mathrm{~mm}$. Katalis yang digunakan yaitu $\mathrm{KOH} 2 \% \mathrm{~b} / \mathrm{b}$ pro analisis sedangkan metanol atau etanol teknis sebagai pereaksi. Transesterifikasi in situ ampas kelapa dilakukan pada temperatur reaksi $65^{\circ} \mathrm{C}$ dan kecepatan pengadukan $1000 \mathrm{rpm}$. Variasi variabel adalah waktu reaksi 4,5,6,7,8,9 jam dan jenis pereaksi yaitu metanol dan etanol teknis. Hasil penelitian ini menunjukan bahwa waktu reaksi dan jenis pereaksi berpengaruh terhadap yield biodiesel. Hasil penelitian menunjukan penggunaan metanol sebagai reaktan menghasilkan yield sebesar $85,97 \%$ sedangkan etanol sebesar $53,57 \%$. Yield biodiesel 85,97\% dengan reaktan metanol dicapai selama 8 jam. Hasil analisis biodiesel tersebut menunjukan bahwa nilai densitas, kadar air, viskositas memenuhi standar SNI Biodiesel No.7182-2012 sedangkan untuk gliserol total, dan bebas tidak memenuhi SNI.
\end{abstract}

Kata Kunci : biodiesel, ekstraksi reaktif, ampas perasan kelapa

\section{PENDAHULUAN}

Ampas perasan kelapa adalah limbah pembuatan santan, yang sangat potensial dalam pembuatan biodiesel [1]. Menurut Sulaiman [2], kandungan minyak dalam ampas perasan kelapa berkisar antara 17$24 \%$, sehingga berpotensi digunakan sebagai bahan baku pembuatan biodiesel.

Pada proses pembuatan biodiesel secara konvensional, minyak sebagai bahan baku pembuatan biodiesel didapatkan dari hasil ekstraksi biji [3]. Minyak yang sudah diekstraksi kemudian direaksikan dengan reaktan dan katalis untuk memproduksi biodiesel. Pada metoda ekstraksi reaktif (transesterifikasi insitu), reaktan langsung dikontakkan dengan biji-bijian yang mengandung minyak dimana reaktan berfungsi sebagai pelarut sekaligus reaktan. Metoda ini menggabungkan antara proses ekstraksi dan reaksi dalam satu tahap [4].

Pada penelitian ini bahan baku yang digunakan adalah ampas perasan kelapa, pereaksi etanol dan metanol, katalis $\mathrm{KOH} 2 \%$ berat, kecepatan pengadukan $1000 \mathrm{rpm}$ dan temperatur reaksi $65^{\circ} \mathrm{C}$.

Tujuan dari penelitian ini adalah menentukan waktu reaksi optimum yang menghasilkan yield biodiesel tertinggi dan jenis pereaksi yang dapat menghasilkan yield biodiesel lebih besar. Manfaat penelitian ini adalah membantu pemerintah dalam pengurangan konsumsi bahan bakar fosil dengan cara pemakaian energi terbarukan yaitu pembuatan biodiesel dan meningkatkan nilai ekonomis dari limbah padat ampas perasan kelapa.

\section{METODE}

Metode penelitian yang digunakan pada penelitian ini merupakan metode eksperimental yang terdiri dari beberapa tahap berkesinambungan agar tujuan penelitian dapat tercapai. Tahap I adalah persiapan bahan baku yang terdiri dari penentuan kadar air minyak, bilangan asam, $\%$ Free Fatty Acid, kandungan minyak, diameter partikel ampas perasan kelapa.

Penentuan kandungan minyak pada ampas perasan kelapa dilakukan dengan 2 
metode yaitu sokletasi dan mixing extraction dengan pelarut n-hexane. Metode yang menghasilkan yield minyak lebih besar digunakan sebagai perhitungan yield biodiesel.

Sokletasi adalah suatu metode pemisahan komponen yang terdapat dalam sampel padat dengan cara ekstraksi berulang-ulang dengan pelarut yang sama, sehingga semua komponen yang diinginkan dalam sampel terisolasi dengan sempurna. Alat yang digunakan adalah seperangkat alat sokletasi yang terdiri atas labu didih, tabung soklet, dan kondensor seperti pada Gambar 1 .

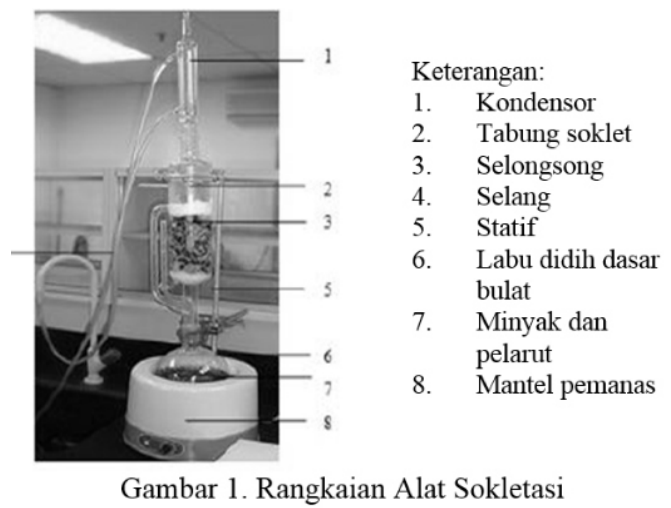

Mixing extraction (Gambar 2) merupakan metode pemisahan komponen kimia yang dilakukan dengan cara merendam serbuk bahan dalam pelarut selama waktu tertentu yang dibantu dengan pengadukan pada kecepatan pengadukan tertentu. Campuran serbuk bahan dengan pelarut kemudian dipisahkan dengan proses penyaringan. Filtrat didistilasi untuk memisahkan pelarut dari komponen yang diinginkan.

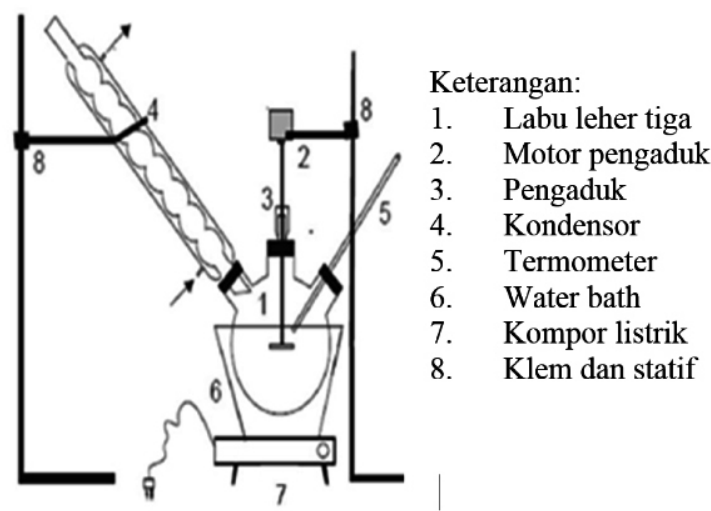

Gambar 2. Rangkaian Alat Mixing Extraction
Tahap 2 adalah proses pembuatan biodiesel dengan metode ekstraksi reaktif. Pada metoda ekstraksi reaktif, minyak dari ampas perasan kelapa langsung dikontakkan reaktan. Metoda ini menggabungkan antara proses ekstraksi dan reaksi dalam satu tahap. Proses ini akan meningkatkan efisiensi karena tidak membutuhkan pelarut tambahan dan adanya efisiensi peralatan.

Proses ekstraksi reaktif dilakukan dengan 2 metode yaitu mixing reactor dan sokletasi. Hal ini digunakan untuk menentukan metode yang menghasilkan yield biodiesel lebih besar. Penelitian ini dilakukan dengan memvariasikan waktu reaksi dan jenis pereaksi. Sebanyak 35 gram ampas perasan kelapa dilarutkan dalam $300 \mathrm{ml}$ pereaksi metanol dan katalis $\mathrm{KOH} 2 \%$ b/b dalam labu leher 4, kemudian direaksikan dengan waktu reaksi bervariasi yaitu 4,5,6,7,8, dan 9 jam. Percobaan yang sama diulangi menggunakan pelarut etanol.

Produk yang dihasilkan disaring untuk dipisahkan ampasnya. Produk bebas ampas dipisahkan dari sisa pelarut dengan cara destilasi pada suhu yang sesuai dengan titik didih pelarut $\left(65^{\circ} \mathrm{C}\right.$ untuk metanol dan $80^{\circ} \mathrm{C}$ untuk etanol). Hasil distilasi berupa biodiesel dan gliserol bebas pelarut. Biodiesel dapat dipisahkan dari gliserol dengan cara dekantasi menggunakan corong pisah. Gliserol dan biodiesel yang terbentuk masing - masing ditimbang. Biodiesel kemudian dianalisis sifat fisik dan kimia untuk mengetahui kualitasnya.

Tahap 3 adalah metode analisis biodiesel meliputi massa jenis, kadar air (AOAC 1995), gliserol bebas (SNI 7182:2012), viskositas (metode oswalt) dan gliserol total (SNI 7182:2012). Selanjutnya hasil analisis tiap analisis biodiesel dibandingkan dengan standar mutu biodiesel SNI $7182: 2012$.

Pada pengolahan data untuk perhitungan yield biodiesel didapatkan menggunakan persamaan [5]:

biodiesel $(\%)=$ Massa biodiesel (gram) $\times 100 \%$ Massa minyak b.baku (gram) 


\section{HASILDAN PEMBAHASAN}

Hasil karakterisasi bahan baku menunjukan bahwa ampas perasan kelapa memiliki kandungan minyak dengan metode sokletasi sebesar 32\%-b/b sedangkan dengan metode mixing reactor sebesar $10,57 \%-b / b$. Perbedaan hasil perolehan kandungan minyak terjadi karena pada metode sokletasi, ekstraksi terjadi secara berulang sehingga minyak yang terkandung pada ampas perasan kelapa terekstrak secara sempurna sementara pada metode mixing extraction minyak yang terekstrak tidak dilakukan berulang dan membutuhkan proses pemurnian antara ampas dan minyak. Kandungan minyak ampas perasan kelapa metode sokletasi memiliki nilai bilangan asam $0,54 \mathrm{mg} \mathrm{KOH} / \mathrm{g}$ dan asam lemak bebas 0,19\%-b. Nilai bilangan asam dan asam lemak bebas tersebut telah memenuhi persyaratan bahan baku untuk digunakan dalam proses transesterifikasi yaitu angka asam $<1 \mathrm{mg}$ $\mathrm{KOH} / \mathrm{g}$ dan kadar asam lemak bebas $<0,5 \%$ $\mathrm{b} / \mathrm{b}$ selain itu juga kadar air minyak ampas perasan kelapa adalah 0,01\%. Angka ini telah memenuhi persyaratan kadar air dalam bahan baku untuk proses transesterifikasi yaitu kurang dari 0,3\% [6].

Penentuan diameter partikel bahan baku dilakukan berdasarkan metode sizing. Pengolahan data untuk menentukan diameter partikel ampas perasan kelapa menggunakan grafik $80 \%$ lolos komulatif. Metode tersebut dilakukan untuk mengetahui ukuran partikel ampas perasan kelapa. Hasil percobaan menunjukan diameter partikel ukuran ampas perasan kelapa sebesar 1,12 mm. Dalam pelaksanaan penelitian, semua ukuran partikel bahan baku digunakan.

Pembuatan biodiesel dengan metode ekstraksi reaktif dengan mixing reactor menghasilkan yield sebesar $66,29 \%$, sedangkan sokletasi sebesar 23,27\%. Hal ini disebabkan karena faktor pengadukan dapat membantu proses reaksi pembuatan biodiesel. Berdasarkan yield tersebut maka pada penelitian selanjutnya digunakan menggunakan mixing reactor.

\section{Pengaruh Waktu Reaksi dengan Pereaksi Metanol}

Gambar 3 menunjukan bahwa semakin lama waktu reaksi, maka semakin besar pula yield pembentukan biodiesel tetapi setelah 8 jam yield cenderung konstan. Hal ini disebabkan karena kesetimbangan reaksi sudah tercapai dalam waktu 8 jam. Pada waktu reaksi 8 jam, diperoleh yield biodiesel sebesar $85,97 \%$.

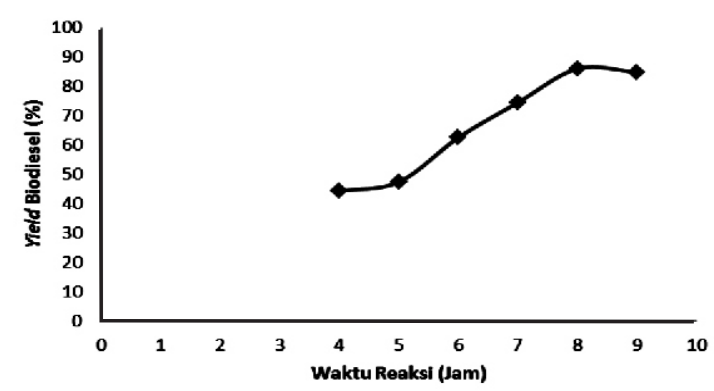

Gambar 3. Kurva Waktu Reaksi terhadap Yield Biodiesel dengan Pereaksi Metanol

Berdasarkan Tabel 1 dapat dilihat bahwa massa jenis, viskositas kinematik dan kadar air telah memenuhi standar mutu biodiesel, sedangkan kadar gliserol total yang memenuhi standar adalah pada waktu reaksi 4 jam. Waktu reaksi 5-9 jam memiliki kandungan gliserol total yang melebihi standar mutu. Kandungan gliserol yang masih melebihi standar mutu biodiesel menunjukan masih banyaknya sisa trigliserida, digliserida, monogliserida yang tidak terkonversi menjadi biodiesel.

Tabel 1. Hasil Analisis Kualitas Biodiesel dengan Pereaksi Metanol

\begin{tabular}{|c|c|c|c|c|c|c|}
\hline $\begin{array}{c}\text { Wakt } \\
\text { u } \\
\text { reaksi } \\
\text { (jam) }\end{array}$ & $\begin{array}{c}\text { Massa } \\
\text { jenis } \\
(\mathrm{kg} / \mathrm{m} \\
3)\end{array}$ & $\begin{array}{c}\text { Glise } \\
\text { rol } \\
\text { Total } \\
(\%- \\
\mathrm{m})\end{array}$ & $\begin{array}{c}\text { Glis } \\
\text { erol } \\
\text { Beb } \\
\text { as } \\
(\%- \\
\mathrm{m})\end{array}$ & $\begin{array}{c}\text { Gliser } \\
\text { ol } \\
\text { Terika } \\
\mathrm{t} \\
(\% \mathrm{~m})\end{array}$ & $\begin{array}{c}\text { Vis } \\
\text { kosi } \\
\text { tas } \\
\text { Kin } \\
\text { ema } \\
\text { tik } \\
\text { (Cst } \\
\text { ) }\end{array}$ & $\begin{array}{l}\text { Kada } \\
\text { r Air } \\
(\%-v)\end{array}$ \\
\hline 4 & 883,23 & 2,31 & 0,20 & 2,11 & 7,83 & 0,04 \\
\hline 5 & 874 & 1,44 & 0,17 & 1,27 & 7,30 & 0,04 \\
\hline 6 & 876,85 & 2,05 & 0,03 & 2,01 & 6,77 & 0,04 \\
\hline 7 & 876,11 & 2,23 & 0,14 & 2,09 & 6,62 & 0,09 \\
\hline 8 & 886,25 & 2,21 & 0,45 & 1,76 & 5,36 & 0,02 \\
\hline 9 & 877,84 & 2,22 & 0,16 & 2,06 & 4,70 & 0,02 \\
\hline $\begin{array}{c}\text { Standa } \\
\mathrm{r}\end{array}$ & $\begin{array}{l}850- \\
890\end{array}$ & 0,24 & 0,02 & & $\begin{array}{c}2,3- \\
6,0\end{array}$ & 0,05 \\
\hline
\end{tabular}




\section{Pengaruh Waktu Reaksi dengan Pereaksi Etanol}

Semakin lama waktu reaksi maka semakin besar pula yield yang dihasilkan (Gambar 4). Pada waktu reaksi 4 sampai 7 jam, yield biodiesel terus meningkat, namun pada waktu reaksi 8 dan 9 jam yield menurun. Hal ini disebabkan kesetimbangan reaksi sudah tercapai dalam waktu 7 jam. Pada waktu reaksi 7 jam yield biodiesel yang diperoleh adalah 53,56\%.

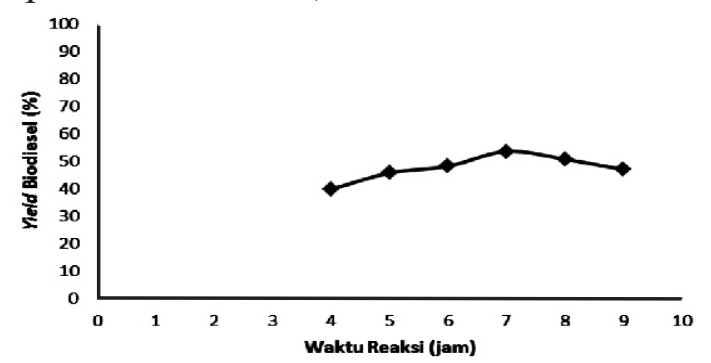

Gambar 4. Kurva Waktu Reaksi terhadap Yield Biodiesel dengan Pereaksi Etanol

Berdasarkan Tabel 2 dapat dilihat bahwa kadar air yang sesuai dengan standar mutu biodiesel adalah pada waktu reaksi 4,5,6,8 dan 9 jam. Akan tetapi, pada waktu reaksi 7 kadar air melebihi standar mutunya yaitu $0,05 \%$-v. Viskositas kinematik biodiesel yang memenuhi standar mutu adalah pada 8 dan 9 jam, sedangkan pada waktu reaksi lainnya tidak memenuhi persyaratan. Hal ini disebabkan reaksi penyabunan pada produk biodiesel sehingga meningkatkan viskositas produk. Hasil analisis pada Tabel 3 memperlihatkan bahwa biodiesel yang dihasilkan tidak memenuhi persyaratan untuk kadar gliserol total dan gliserol bebas. Hal ini disebabkan oleh konversi yang tidak sempurna selama reaksi transesterifikasi in situ atau pemisahan yang tidak sempurna antara gliserol dan biodiesel.

Tabel 2. Hasil Analisis Kualitas Biodiesel dengan

\begin{tabular}{ccccccc}
\multicolumn{7}{c}{ Pereaksi Etanol } \\
\hline $\begin{array}{c}\text { Waktu } \\
\text { reaksi } \\
(\mathbf{j a m})\end{array}$ & $\begin{array}{c}\text { Massa } \\
\text { jenis } \\
(\mathbf{k g} / \mathbf{m} \mathbf{3})\end{array}$ & $\begin{array}{c}\text { Gliserol } \\
\text { Total } \\
(\% \mathbf{\%}-\mathbf{m})\end{array}$ & $\begin{array}{c}\text { Gliserol } \\
\text { Bebas } \\
(\%-\mathbf{m})\end{array}$ & $\begin{array}{c}\text { Gliserol } \\
\text { Terikat } \\
(\% \mathbf{m})\end{array}$ & $\begin{array}{c}\text { Viskositas } \\
\text { Kinematik } \\
(\mathbf{C s t})\end{array}$ & $\begin{array}{c}\text { Kadar } \\
\text { Air } \\
(\%-\mathbf{\%})\end{array}$ \\
\hline $\mathbf{4}$ & 851,39 & 0,16 & 0,03 & 0,12 & 3,38 & 0,01 \\
$\mathbf{5}$ & 852,64 & 0,81 & 0,03 & 0,78 & 2,67 & 0,01 \\
$\mathbf{6}$ & 851,79 & 2,17 & 0,21 & 1,96 & 2,92 & 0,01 \\
$\mathbf{7}$ & 859,43 & 0,51 & 0,03 & 0,48 & 3,29 & 0,01 \\
$\mathbf{8}$ & 867,64 & 2,13 & 0,19 & 1,94 & 2,48 & 0,01 \\
$\mathbf{9}$ & 853,25 & 1,65 & 0,07 & 1,58 & 2,88 & 0,01 \\
Standar & $850-890$ & 0,24 & 0,02 & & $2,3-6,0$ & 0,05 \\
\hline
\end{tabular}

\section{Perbandingan Metanol dan Etanol}

Kondisi optimum ditentukan berdasarkan yield tertinggi dari pereaksi metanol dan etanol. Kondisi optimum dengan pereaksi metanol terjadi pada waktu reaksi 8 jam dan menghasilkan yield sebesar 85,97\%, sedangkan kondisi optimum dengan pereaksi etanol terjadi pada, waktu reaksi 7 jam dengan yield sebesar 53,56\%. Yield optimum dengan pereaksi metanol 85,97\% lebih besar daripada pereaksi etanol 53,56\% pada kondisi operasi diperoleh pada kondisi operasi suhu reaksi $65^{\circ} \mathrm{C}$, pengadukan $1000 \mathrm{rpm}$, waktu reaksi 8 jam. Metanol menghasilkan yield yang lebih tinggi karena mempunyai rantai yang lebih pendek sehingga lebih mudah bereaksi dengan trigliserida [7].

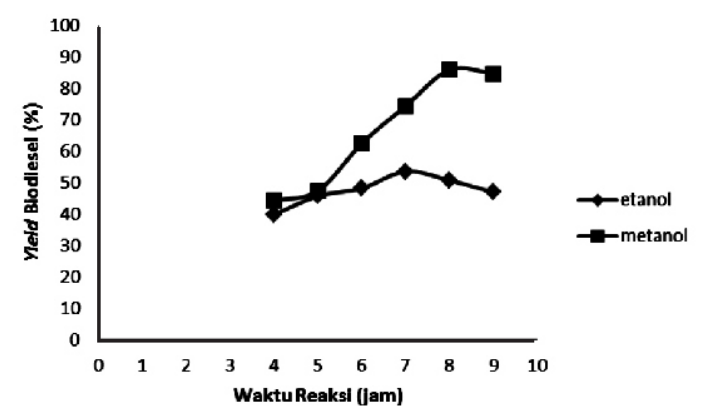

Gambar 6. Kurva Waktu Reaksi terhadap Yield Biodiesel dengan Pereaksi Etanol dan Metanol

\section{SIMPULAN}

Kesimpulan yang diperoleh dari penelitian adalah sebagai berikut:

1. Waktu reaksi optimum yang menghasilkan yield biodiesel tertinggi diperoleh selama 8 jam dengan metanol sebagai pelarut. Yield biodiesel yang dihasilkan sebesar 85,97\% dan kualitas biodiesel sesuai dengan Standar Nasional Indonesia (SNI) pada parameter densitas $867,64 \mathrm{~kg} / \mathrm{m} 3$, viskositas 2,48 cst, kadar air 0,01\% sementara itu untuk gliserol total 2,13 $\%$, gliserol bebas $0,19 \%$, gliserol terikat $1,94 \%$ belum memenuhi standar.

2. Yield biodiesel optimum dengan 
pereaksi metanol $(85,97 \%)$ lebih besar daripada etanol $(53,56 \%)$. Hal ini disebabkan reaktivitas metanol lebih besar daripada etanol.

\section{DAFTAR PUSTAKA}

]1] Piyanuch Nakpong, Sasiwimol Wootthikanokkhan, 2010, High Free F a t ty Acid Coconut Oil as A Potential Feedstock for Biodiesel Production in Thailand, Journal Renewable Energy 35, 1682-1687.

]2] Sarina Sulaiman, A.R. Abdul Aziz, Mohamed Kheireddine Aroua, 2013, Reactive Extraction of Solid Coconut Wa s te to Produce Biodiesel, Journal of $t h \quad e$ Taiwan Institute of Chemical Engineers 44, 233-23.

[3] Jyati Porwal, Dinash Bangwal, Harvey A.P., Lee G.M, Reactive Extraction of Pongamia Seeds for Biodiesel Production, 2012, Journal of Scientific \& Industrial Research, 71, 822-828.

]4] Rabitah Zakaria, Adam P. Harvey, 2014, Kinetics of Reactive Extraction/ In situ Transesterification of Rapeseed Oil, Fuel Processing Technology 125, 34-40

15] A.M. Liaquat, H.H. Masjuki, M.A. Kalam, I.M. Rizwanul Fattah, M.A. Hazrat,

\section{UCAPAN TERIMA KASIH}

Penulis mengucapkan terima kasih Direktorat Perguruan Tinggi (DIKTI) yang telah membantu dalam pendanaan pada penelitian

M. Varman, M. Mofijur, M. Shahabuddin, 2013, Effect of Coconut $\quad$ B i o d i e s e 1 Blended Fuels on Engine Performance and Emission Characteristics. 5th BSME International $\mathrm{C}$ o $\mathrm{n} \mathrm{fer} \mathrm{e} \mathrm{n} \mathrm{ce}$ o n Thermal Engineering, Procedia Engineering $56,583-590$.

]6] João Felipe G. Oliveira, Izabelly Larissa Lucena, Rosana M. Alves Saboya, Marcelo L.Rodrigues, Antonio Eurico B. Torres, Fabiano A. NarcisoFernandes, Célio L. Cavalcante Jr, Expedito José S.ParenteJr, 2010, Biodiesel Production from Waste Coconut Oil by Esterification with Ethanol: The Effect to Water Removal by Adsorption, Renewable Energy 35, 2581-2584

17] Sarina Sulaiman, A.R. Abdul Aziz, Mohamed Kheireddine Arou, 2013, Optimization and Modeling of Extraction of Solid Coconut Waste Oil, Journal of Food Engineering 114, 228-234 